\title{
Comunicação e educação para a cidadania em uma cooperativa de assentamento do $\mathrm{MST}^{1}$
}

Luzia M. Yamashita Deliberador

Doutora em Ciência da Comunicação pela ECA/USP.

Professora do Curso de Especialização em Comunicação Popular e

Comunitária da Universidade Estadual de Londrina/PR.

Diretora-presidente da Unimares - União Maringaense de Ensino, mantenedora da Faculdade Cidade Verde, Maringá/PR.

E-mail: adeli@sercomtel.com.br

Ana Carolina Rampazzo Vieira

Pedagoga, especialista em Comunicação Popular e Comunitária pela Universidade Estadual de Londrina.

E-mail: krol_rv@yahoo.com.br

Os objetos de análise deste artigo são a estrutura e o funcionamento da Cooperativa de Produção Agropecuária Vitória Ltda. - COPAVI, assentamento do Movimento dos Trabalhadores Rurais Sem-Terra - MST localizado no município de Paranacity, Paraná. Buscou-se analisar especificamente o acompanhamento pedagógico realizado pelos educadores/pedagogos da comunidade com crianças e pré-adolescentes de 5 a 12 anos.

O objetivo é verificar como a concepção de educação do MST, seus princípios filosóficos e pedagógicos e sua metodologia educativa são executados pelo Setor de Educação da COPAVI, procurando divulgar no meio acadêmico o seu trabalho como assentamento-modelo na atividade coletiva e no desenvolvimento da cidadania.

A atividade foi desenvolvida por meio de pesquisa participativa, entrevistas e observações junto aos moradores da COPAVI. Foram muitas visitas e também uma convivência de mais de quatro anos, em que se desenvolveram pesquisas e orientações de trabalhos de conclusão de curso e monografias de pós-graduação.

Na maior marcha de reivindicação social da história do País, o MST levou a Brasília 12 mil militantes ${ }^{2}$, de 22 estados, que percorreram 205 quilômetros em dezesseis dias para cobrar reforma agrária. Que outro movimento social conseguiria essa realização?

A organização e a disciplina no movimento são necessárias para se conseguir uma mobilização desse porte, a qual foi motivo de admiração no exterior. No entanto, no Brasil, muitas vezes o MST é ignorado ou malfalado pela mídia.

1. Trabalho apresentado ao NP 11 - Comunicação Educativa, do $\mathrm{V}$ Encontro do Núcleo de Pesquisa da Intercom.

2. ATHAYDE, Phydia. Marcha e Vida Severina, MST. Um relato sobre os últimos 3 dias da histórica caminhada que levou 12 mil militantes a Brasília para cobrar reforma agrária. Revista Carta Capital, São Paulo, ano XI, n. 343, p. 24 a 31, 25 maio 2005. 
comunicação \& educação • Ano XI • Número 3 • set/dez 2006

3. PERUZZO, Cecília M. K. Comunicação comunitária e educação para a cidadania. Revista Fronteiras: estudos midiáticos. São Leopoldo: Unisinos, v. 3, n. 1, p. 120, set. 2001.

4. FREIRE, Paulo. Pedagogia do oprimido. Rio de Janeiro: Paz e Terra, 1978.

5. TRIÁLOGOS - Reportagem Especial, MST: Da Luta pela Terra à Luta na Terra. Projeto Comunicação e Educação: Um Diálogo Escola-Mídia-Universidade. Departamento de Comunicação. Londrina: Universidade Estadual de Londrina, dez. 2000. p. 12.
A luta pela cidadania acontece no cotidiano do grupo, afetando a vida de cada indivíduo envolvido. Na Cooperativa de Produção Agropecuária Vitória - COPAVI, isso não é mera convicção teórica. Ao contrário, realiza-se através do diálogo, do respeito e, principalmente, quando cada um cumpre rigorosamente os seus deveres, fazendo com que os direitos se tornem realidade.

Essa adesão é notada na maneira própria de pensar, sentir, agir e viver dos indivíduos da comunidade; para eles, a luta para estabelecer a consciência dos indivíduos com o compromisso de promoção da cidadania e dos direitos humanos inclui obrigatoriamente a educação formal e informal.

Segundo Peruzzo, "é no âmbito da educação informal que estaremos enfocando as questões das relações entre comunicação e educação no processo de conquista de cidadania”. É justamente nesses espaços populares que os indivíduos se educam através da interação com os outros. E na COPAVI eles se reconhecem enquanto sujeitos ao participarem ativamente das decisões, o que os leva a assumirem uma postura mais crítica e responsável.

Para Freire 4 , todo ato educativo é um ato político e todo ato político é um ato educativo. A educação para cidadania deve educar os indivíduos para a ação político-social coletiva na luta pela democracia.

A COPAVI é uma cooperativa importante do ponto de vista econômico e político. Tem uma boa gestão administrativa e consegue viabilizar economicamente o assentamento, com uma importante produção agroindustrial. Claro que para que isso ocorra existe uma estrutura organizacional, a qual tem como origem a própria organização e a filosofia do MST.

A COPAVI acaba demonstrando que a reforma agrária é uma luta de todos. É uma luta dos sem-terra, mas é também uma luta de toda a população que acaba se beneficiando com bons produtos a preços acessíveis. Em Paranacity, a comunidade já provou isso.

Para alcançar as metas definidas, os integrantes da cooperativa seguem rigorosamente a filosofia definida pelo MST:

- Respeito ao meio ambiente: produzir sem agredir o meio ambiente. A preocupação com o desenvolvimento auto-sustentável é constante. Trabalham na recuperação do solo muitas vezes até em detrimento do lucro imediato. A horta do assentamento é totalmente orgânica.

- Trabalho coletivo: o trabalho coletivo converge para a cidadania articulada, que concilia o bem comum ao particular. Esses cooperados têm uma opção ideológica clara - o socialismo -, que fortalece o processo de produção e as tomadas de decisão conjuntas. São "uma empresa de cunho socialista, cujo esforço é centrado nas pessoas que a compõem”, explica o cooperado engenheiro agrônomo Élson Borges dos Santos, o Zumbi.

- Gênero e participação igualitária: "Trabalhar com a perspectiva de gênero é reconhecer que a manutenção de hierarquia entre homens e mulheres é fiel guardiã das demais relações de opressão e exploração existentes na sociedade" ${ }^{5}$.

$\mathrm{Na}$ organização da cooperativa, a mulher associada está em condições de igualdade com o homem: $50 \%$ está em nome dela e 50\%, em nome dele. 
O almoço e o café da manhã são coletivos na COPAVI. Duas cooperadas são escaladas para o refeitório e o trabalho delas tem o mesmo valor de que em qualquer outro setor da cooperativa. Com isso as demais mulheres ficam dispensadas das atividades diárias de cozinhar e lavar louça, e podem participar ativamente em vários âmbitos de produção da cooperativa. As refeições coletivas apresentam algumas vantagens, tais como a convivência como uma grande família, em que se trocam idéias, experiências, propiciando uma interação maior entre os membros da comunidade. As mulheres tomam parte em todo o processo decisório da cooperativa, nas transformações políticas, econômicas e sociais, inclusive ocupam cargos de diretoria. As refeições noturnas são preparadas em casa para que cada cooperado possa ter um espaço de convivência com sua própria família.

Essas metas e diretrizes da cooperativa são também os alicerces para a educação das crianças e jovens da comunidade.

\section{COPAVI - COOPERATIVA DE PRODUÇÃO AGROPECUÁRIA VITÓRIA LTDA.}

A Fazenda Santa Maria, com uma área de 256,52 hectares de terra, pertencente ao município de Paranacity, a $110 \mathrm{~km}$ da cidade de Maringá, foi declarada latifúndio por exploração e desapropriada em 30 de junho de 1988. Apesar de reconhecida como área de interesse social para fins de reforma agrária no mesmo ano pelo Instituto Brasileiro de Colonização e Reforma Agrária - Incra, a desapropriação foi contestada judicialmente e a fazenda, arrendada à Usina Santa Terezinha. Mediante decisão judicial, o Incra recebeu a emissão de posse da terra em 27 de agosto de 1992.

Em 19 de janeiro do ano seguinte, 25 famílias pertencentes ao Movimento dos Trabalhadores Rurais Sem-Terra reivindicaram o uso da terra. A área era totalmente ocupada pela cana-de-açúcar, o que deixou o solo bastante desgastado. Em 1994, depois de quase um ano acampadas em barracas de lona, as famílias receberam do Incra os títulos de propriedade de terra e a liberação de financiamentos.

As famílias se uniram e criaram a Cooperativa de Produção Agropecuária Vitória - COPAVI, optando pela organização em cooperativa de produção. Os trabalhadores decidiram não dividir a fazenda em lotes individuais, mas registrar o título de concessão de uso da terra em nome da própria cooperativa. E com isso deram início às atividades produtivas. Todas as famílias são proprietárias da terra, e cada integrante delas é sócio da empresa e pode participar das decisões tomadas em assembléias.

A COPAVI constituiu uma empresa de produção e trabalhos coletivos. A terra permanece sobre o controle do coletivo, a não ser uma pequena parcela destinada à produção de fundo de quintal de cada associado.

O trabalho organiza-se internamente através de setores de produção e serviços. A remuneração é proporcional ao número de horas trabalhadas, que são controladas pelos coordenadores dos setores. 
comunicação \& educação • Ano XI • Número 3 • set/dez 2006

O planejamento da produção é centralizado no coletivo. A partir de uma grande discussão, baseada em estudos técnicos, definiram-se as linhas de produção a curto, médio e longo prazos e a ordem das prioridades a serem implantadas.

A moradia é organizada em agrovila, com lotes de tamanho definido pelo coletivo, e as residências foram construídas por eles mesmos, de forma bem simples. São casas de alvenaria com luz elétrica, fossa séptica e água encanada. Atualmente estão construindo novas moradias através de financiamentos da Companhia de Habitação do Paraná - Cohapar.

O assentamento é composto por 89 pessoas que são sócias da cooperativa, em um total de 21 famílias. A população ativa constitui a maioria desse número, somando-se a ela 25 crianças entre 5 e 12 anos. Hoje a COPAVI é um exemplo nacional e internacional de cooperativa de produção, reconhecida e visitada por muitas pessoas, desde crianças em excursões escolares, jovens estudantes de outros países, que ficam alojados na comunidade para estágios, e universitários brasileiros da região e até de outros estados. O que antigamente era preconceito, hoje se transformou em orgulho para a região.

\section{PRODUÇÃO}

As atividades exploradas são diversificadas:

1. a bovinocultura de leite (ocupando uma área de 45 hectares) já representou a atividade de maior importância econômica. Hoje perde para os produtos derivados da cana-de-açúcar, mas o assentamento continua sendo o maior produtor de leite pasteurizado da região, com média de 650 litros de leite diários distribuídos na cidade de Paranacity e redondeza. Com a produção de leite os cooperados ainda fabricam iogurte, queijo e doce de leite. O iogurte é distribuído para a merenda escolar através de um convênio com o governo federal.

2. o plantio de cana-de-açúcar (30 hectares) é responsável pela produção de 15 toneladas de açúcar mascavo, distribuídas para várias regiões do País, e seis mil litros de cachaça artesanal, hoje exportada para a Espanha.

3. a panificadora produz pães e biscoitos que são vendidos para a merenda escolar de Paranacity, de Cruzeiro do Sul e ainda no mercado regional.

4. a banana desidratada também era um produto produzido pela cooperativa e muito conhecido na região. A fabricação teve de ser suspensa por causa de uma praga que atacou os bananais. Os cooperados pretendem recomeçar o plantio de variedades mais resistentes.

5. a produção de hortaliças orgânicas, em cujo cultivo não são utilizados adubos químicos, inseticidas ou agrotóxicos. Para proteger as hortaliças das pragas e das doenças provocadas por insetos diversos, são empregados inseticidas naturais, como o cravo-de-defunto, a arruda e o fumo. Essas plantas combatem as pragas repelindo os insetos de modo menos agressivo para o meio ambiente e ideal para a agricultura orgânica. Não são usados adubos químicos, e sim o esterco do gado que é transformado 
em adubo, pois é próprio para estimular o crescimento das verduras e legumes. A horta está cercada por uma barreira de plantas - o chamado quebra-vento - para diminuir a incidência de insetos. O lema deles é $A$ natureza cuida da natureza e, com isso, conseguem produtos mais saudáveis para o homem. De tudo que se produz na horta, $15 \%$ é para o consumo interno e $85 \%$ para comercialização na feira livre da cidade.

6. a produção de carnes de frango e porco supre as necessidades do consumo interno e o excedente é comercializado.

Descontadas todas as despesas administrativas e de produção, a renda per capita de cada família associada é de $R \$ 700,00$. A remuneração é em função do número de horas trabalhadas, como já citado.

\section{ORGANIZAÇÃO E FUNCIONAMENTO DA COOPERATIVA}

A Assembléia é o órgão deliberativo máximo da cooperativa, e suas reuniões são realizadas mensalmente. Existe também o Conselho Deliberativo, formado por um coordenador de cada setor, um coordenador de cada núcleo e um membro da diretoria. Há ainda o Conselho Fiscal, composto por três membros efetivos e três suplentes, eleitos em assembléia com mandato de três anos, cuja função é acompanhar todo o setor financeiro e fiscalizar a atuação no trabalho de cada sócio.

\section{SISTEMA DE TRABALHO}

Não há remuneração diferenciada entre os setores de produção, direção e negócios. Divididos por habilidades, os cooperados se adaptam à atividade com a qual melhor se identificam e se aperfeiçoam nela. Os cooperados trabalham oito horas diárias e aos sábados, até o meio-dia. Além disso, algumas tarefas que requerem cuidados constantes como a horta e as criações são atendidas em sistema de rodízio.

Todos os sócios têm direito a trinta dias de férias não-remuneradas. Até os 18 anos a prioridade é a educação. Caso o adolescente queira trabalhar, primeiramente se realiza uma conversa com os pais e o orientador pedagógico. Verificando-se que o trabalho a ser realizado não afetará o rendimento escolar, o serviço é autorizado e planejado. Dos 17 aos 18 anos é obrigatória a atividade de cem horas mensais, com remuneração equivalente à dos adultos. Para os adolescentes na faixa etária entre 14 e 16 anos, o trabalho não é obrigatório e, caso o exerçam, o valor da hora de trabalho corresponde a $70 \%$ da hora paga a um adulto.

\section{PARTICIPAÇÃO NA SOCIEDADE}

Paranacity tem oito mil habitantes e a COPAVI possui um representante eleito com os votos da cooperativa e da população da cidade. Trata-se de An- 
tonio Soares, o Sacola, vereador que posteriormente passou pela presidência da Câmara Municipal. Ele foi membro da direção estadual do MST (1994-1996) e é conhecido por trabalhar na comercialização e entrega dos produtos da cooperativa na cidade de Paranacity. A comunidade da cooperativa preocupa-se em mostrar a seriedade do seu trabalho, demonstrando principalmente que a reforma agrária é importante para a sociedade na produção de alimentos de qualidade. Os cooperados procuram com isso provar a todos que são trabalhadores e possuem consciência crítica do seu papel na sociedade.

\section{COMUNICAÇÃO COMUNITÁRIA E COMUNICAÇÃO POPULAR: DIFERENÇAS E SEMELHANÇAS EM SUAS DEFINIÇÔES}

Aparentemente semelhantes, comunicação comunitária e comunicação popular possuem características distintas. Procuraremos ressaltá-las a seguir para melhor compreensão sobre o tipo de comunicação que caracteriza a educação realizada pelo MST, em especial àquela realizada na COPAVI.

À primeira vista, os dois termos parecem sinônimos, tratando de formas de comunicação ligadas à comunidade e visando à cidadania e à participação dos indivíduos. Ambas as denominações se contrapõem ao conceito clássico de comunicação humana (emissor = detentor único da informação; receptor = ouvinte passivo), criando um novo modelo de comunicação, mais humano $\mathrm{e}$ democrático, baseado na troca de informações entre emissor e receptor.

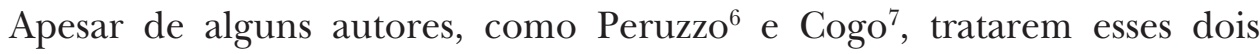
termos como sinônimos, existem certas diferenças bem marcantes entre eles, principalmente com relação às seguintes questões: resistência à classe dominante; conteúdos; público-alvo; caráter político; participação/execução da comunicação.

Em um primeiro momento, quando falamos em comunicação comunitária, pensamos em um processo de comunicação que visa somente noticiar os acontecimentos locais, geralmente deixados em segundo plano pela grande mídia. No entanto, a comunicação comunitária é o canal de expressão de uma comunidade (independentemente de seu nível socioeconômico e território), por meio do qual os próprios indivíduos podem manifestar seus interesses comuns e suas necessidades mais urgentes. Deve ser um instrumento de prestação de serviços e formação do cidadão, sempre com a preocupação de estar em sin-

6. PERUZZO, Cecília M. K. Comunicação e culturas populares. São Paulo: Intercom, 1995. p. 27-41. (GTS - Intercom, 5).

7. COGO, Denise. Comunicação popular: uma retrospectiva. Revista Universidade e Sociedade São Paulo: Andes, n. 11, p. 146-150, jun. 1996. tonia com os temas da realidade local. Por isso, sua característica principal é facilitar/estimular a participação ativa desses indivíduos enquanto produtores e receptores das informações.

Ou seja, o processo de comunicação comunitária deve ser feito pela e para a comunidade, com o compromisso de melhorar o seu desenvolvimento social mediante a busca constante de autonomia, seja sob a forma de co-gestão (participação limitada; poder relativo), seja de autogestão (participação ativa e direta da população nas decisões). É preciso salientar que, via de regra, a 
comunicação comunitária não possui um forte caráter político de luta de classes e de resistência à classe dominante, o que não elimina a possibilidade de imprimi-lo no seu processo.

Assim como a comunicação comunitária, a comunicação popular é antagônica à comunicação de massa e constitui um processo de comunicação horizontal. Entretanto, a comunicação popular possui um público-alvo bem delimitado: as camadas populares mais carentes.

Dessa forma, compreende-se que a comunicação popular é uma comunicação de resistência, reivindicação e pressão, ligada a movimentos populares e à luta de classes, representando um veículo de manifestação de suas causas, anseios e interesses. Sua principal característica é o marcante caráter político, reivindicatório e engajado, trabalhando com conteúdos crítico-emancipatórios a fim de possibilitar uma real conscientização e transformação da comunidade em questão ante as desigualdades sociais, com base em sua organização e educação.

A comunicação popular constitui, portanto, um espaço de comunicação democrática e contextualizada, em que emissores e receptores são os protagonistas, trocando de papel constantemente dentro de um ideal comum. É necessário ressaltar que, diferentemente da comunicação comunitária, a comunicação popular não tem como característica fundamental a participação ativa e exclusiva de indivíduos membros da comunidade, possibilitando a intervenção dos chamados mediadores (terceiros ligados aos movimentos).

Assim, tanto a comunicação comunitária quanto a popular buscam a chamada participação-poder, em que a própria comunidade e seus representantes devem partilhar as decisões e responsabilidades, tomando consciência daquilo que Foucault afirma com excelência: o poder está em cada indivíduo, basta nos unirmos para colocá-lo em prática na luta por nossos anseios.

\section{O MST E A EDUCAÇÃO DO CAMPO}

Inicialmente, a preocupação do MST era apenas com a reforma agrária. Mas ao longo da luta pela terra, o Movimento foi compreendendo que é preciso derrubar não só a cerca do latifúndio, mas também outras cercas que levam o trabalhador do campo a uma injusta e histórica situação de opressão, como a cerca da ignorância ou cerca do latifúndio do saber. Segundo João Pedro Stédile,

[...] só a conquista da terra não seria suficiente para sair da pobreza, para libertar da exclusão. E então o movimento passou a incorporar em seu ideário, em suas necessidades, em sua luta, a conquista da democratização da escola, da educação. Daí passamos também a nos organizar para conquistar a educação ${ }^{8}$.

No entanto, o MST propõe uma educação diferenciada da educação escolar tradicional que, normalmente, atende aos interesses da classe dominante. Segundo Caldart ${ }^{9}$, os trabalhadores do campo devem lutar por políticas públicas adequadas, que garantam seus direitos a uma educação no campo e do campo.
8. PEDAGOGIA do movimento sem-terra: acompanhamento às escolas. Boletim da Educação, São Paulo: MST, p. 69, 2004.

9. KOLLING, Edgar J.; CERIOLI, Paulo R.: CALDART, Roseli (Orgs). Por uma educação no campo Brasília, DF: ANCA, 2002. (Por uma educação no campo/MST, 4). 
comunicação \& educação • Ano XI • Número 3 • set/dez 2006

A Educação do Campo é um processo de aprendizagem que acontece no campo e que é desenvolvido pelos educadores do campo, voltado a atender os educandos que lá moram. Deve acontecer no campo, pois as pessoas têm o direito de estudar onde vivem. Deve ser para o campo, na medida em que é pensada a partir de sua realidade, com a participação dos camponeses e vinculada à sua cultura [...] responde às demandas sociais e humanas dessa população ${ }^{10}$.

Assim, o MST vem lutando pela educação pública e de qualidade em todos os assentamentos/acampamentos e pelo reconhecimento dela pelos órgãos federais. Lutam por políticas públicas e práticas educativas contextualizadas com a realidade dos educandos do meio rural.

Para isso, o Setor de Educação do MST estabeleceu seus próprios princípios filosóficos, pedagógicos e suas linhas metodológicas de trabalho. A seguir, citamo-los de forma sintética.

\section{Princípios filosóficos da educação no MST}

- Educação para a transformação social, conscientização e educação de classe.

- Educação para a formação humana em todas as dimensões (formação ética, humanista e socialista), valorizando os indivíduos enquanto sujeitos.

- Educação como formação/transformação contínua.

\section{Princípios pedagógicos da educação no MST}

- Relação entre teoria e prática visando à formação para a ação transformadora.

- O MST como grande educador dos sem-terra (a luta em si é altamente educativa).

- Relação entre ensino e capacitação.

- Ensino contextualizado com a realidade do campo (conteúdos socialmente úteis).

- Educação para o trabalho e pelo trabalho, com ênfase na cooperação.

- Construção de um ambiente educativo que vincule a escola com os processos políticos, econômicos e culturais.

- Gestão democrática escolar e auto-organização dos educandos.

- Valorização dos conhecimentos e experiências prévias dos alunos, sendo esses os pontos de partida para a elaboração de currículo/conteúdos.

- Valorização das atividades extraclasse para colaborar no desenvolvimento de todo assentamento/acampamento.

- Formação permanente dos educadores e conteúdos pedagógicos.

- Incentivo à pesquisa.

10. PEDAGOGIA..., op. cit., p. 58.
- Trabalho educativo coletivo-cooperativo e individual.

- Constante reflexão sobre as práticas e metodologias educativas. 


\section{Linhas metodológicas do MST}

- Ecletismo metodológico: idéias de Paulo Freire (pedagogia da libertação/ conceito de homem inacabado); de Makarenko (conceito de coletividade e cooperação); de Piaget (construtivismo); de Jose Martí (conceito de nacionalismo e soberania) e de Che Guevara (conceito de revolução e militância).

\section{ACOMPANHAMENTO PEDAGÓGICO NA COPAVI}

De acordo com pesquisa participativa realizada em abril de 2005, constatou-se que moravam no assentamento 25 crianças e pré-adolescentes, sendo eles os educandos que participam das atividades educativas ali desenvolvidas. Essas atividades são ministradas por dois integrantes da própria COPAVI: uma pedagoga formada e um estudante do segundo ano de pedagogia.

Como já citado, o assentamento não possui escola própria devido ao número insuficiente de famílias. Por isso, o trabalho educativo realizado na COPAVI tem caráter informal. Vale salientar que a educação informal não objetiva a reprodução e/ou reforço da escola formal/tradicional e, por isso, não tem seu valor educativo reduzido. Ao contrário, esse tipo de educação, muito comum em movimentos populares - como é o caso do MST -, é de extrema riqueza e valor para os próprios movimentos, já que visa à conscientização e ao estímulo para o reconhecimento dos indivíduos enquanto sujeitos e cidadãos, reforçando sua identidade e procurando despertá-los para todo e qualquer tipo de opressão/dominação.

As aulinhas, termo utilizado pelas próprias crianças e pré-adolescentes da COPAVI quando se referem ao acompanhamento pedagógico realizado no assentamento, acontecem três vezes por semana, com duração de três horas. São feitas diversas atividades teóricas e práticas, sempre contextualizadas com as necessidades e o dia-a-dia do assentamento e a concepção educacional do MST.

É importante destacar que, assim como as demais decisões tomadas pela cooperativa, o planejamento pedagógico também acontece de forma coletiva. Os educadores, pais, educandos e demais membros do assentamento decidem os conteúdos a serem abordados nas aulas, caracterizando a gestão democrática tão defendida pelo MST, em que todos os integrantes, independentemente de idade, sexo e escolaridade, são considerados sujeitos e, por isso, têm suas opiniões ouvidas e respeitadas.

É através desse acompanhamento pedagógico que os educadores procuram colocar os educandos em contato com a história dos movimentos sociais, enfocando principalmente a história de luta do MST pela terra e a história da própria COPAVI. A fala da pedagoga do assentamento ilustra bem a importância desse trabalho, quando diz: "Trabalhamos para que eles conheçam a própria história e valorizem sua origem, que faz parte de sua identidade" (E.A.L., 28 anos). 
Essa valorização da história do MST, seus principais lutadores e sua mística tende a

[...] ajudar a cultivar a memória do MST e do conjunto das lutas populares [...] responsável pela formação da consciência histórica de seus educandos e educadores. Isso implica desenvolver alguns aprendizados básicos: compreender a nossa própria vida como parte da história; respeitar as lições da história; aprender a ver cada ação ou situação numa perspectiva histórica, quer dizer, em um movimento entre passado, presente e futuro, compreendê-las em suas relações com outras ações, situações, uma totalidade maior ${ }^{11}$.

Realizadas no refeitório da COPAVI ou ao ar livre, à sombra das árvores, as atividades pedagógicas do assentamento objetivam formar os indivíduos de forma integral e reforçar a ideologia do Movimento, buscando preparar futuros militantes do MST e desmistificar o caráter pejorativo do termo sem-terrinha, utilizado comumente entre a população da cidade para se referir às crianças da COPAVI. Esse trabalho é de extrema importância já que os educandos freqüentam escolas formais no município de Paranacity e acabam se relacionando com uma realidade social bem diferente da vivida por eles, o que muitas vezes resulta em preconceito por parte dos demais colegas da escola. Segundo um dos educadores: "Com nosso trabalho, conquistamos o respeito da comunidade, e ficou no passado o tempo em que nossas crianças eram chamadas de forma pejorativa de sem-terrinha ou gauchinhos [...]. Hoje, eles têm orgulho de ser chamados assim" (A.V., 23 anos).

Além do estudo da história, da interpretação das músicas/hinos e simbologias do MST, o acompanhamento pedagógico realizado na COPAVI procura estar sempre relacionando à teoria, à prática e ao cotidiano do assentamento. Para isso, procuram destacar as experiências diárias e empregá-las na educação, com o intuito de tornar o ato de aprender mais significativo e útil.

Um bom exemplo disso é a valorização do trabalho no campo, do amor à terra e à natureza, assuntos amplamente discutidos e exaltados durante o acompanhamento pedagógico. Desde cedo, as crianças são estimuladas a participar das atividades da cooperativa e a entender o seu funcionamento. Por isso, durante as aulas práticas, os educandos vão a campo para auxiliar na horta e em outras tarefas compatíveis com a sua idade. Cooperação e solidariedade são palavras de ordem em todas as atividades.

Segundo os educadores, a metodologia utilizada por eles segue as idéias de Paulo Freire, um dos educadores mais valorizados e respeitados pelo MST. Sua pedagogia - a pedagogia do oprimido - baseia-se em comunicação, interação e diálogo aberto entre educador e educando. Para Freire, a educação deve ser

11. INSTITUTO Técnico de Capacitação e Pesquisa da Reforma Agrária - Iterra. Caderno do Iterra. Veranópolis, $\mathrm{RS}, \mathrm{v} .1, \mathrm{n} .2$, p. 17, maio 2001

12. FREIRE, Pedagogia do oprimido..., op. cit., p. 78-79. feita através da comunicação horizontal, na base de trocas de informações e conhecimentos entre os indivíduos envolvidos no ato educativo e o mundo.

O educador já não é o que apenas educa, mas o que, enquanto educa, é educado, em diálogo com o educando, que ao ser educado, também educa. Ambos, assim, se tornam sujeitos do processo em que crescem juntos [...] os homens se educam em comunhão, mediatizados pelo mundo $^{12}$. 
É através de uma educação horizontal que o educador poderá realizar uma ação pedagógica mais eficiente e contextualizada. Essa ação, chamada por Paulo Freire de ação cultural revolucionária, deve se dar através da palavra e do diálogo (comunicação). Possui forte dimensão política, já que seu fim deve ser a libertação de oprimidos e opressores, humanizando ambas as partes.

É justamente o caráter libertador da pedagogia freiriana que é considerado pela pedagoga da COPAVI a peça-chave para a formação crítica dos educandos, pois é muito importante que os alunos, mesmo os muito jovens, sintam-se estimulados a lutar na prática pelas transformações necessárias para a conquista da cidadania dos sem-terra.

Freire é enfático ao afirmar que se torna necessária não só a tomada de consciência de toda essa opressão por que passam (reflexão), mas também é preciso ultrapassar o plano do discurso, colocá-lo em prática (ação) para daí transformar a realidade (pedagogia da práxis): "Não há revolução com verbalismo, nem tampouco com ativismo, mas com práxis, portanto, com reflexão e ação incidindo sobre as estruturas a serem transformadas" ${ }^{13}$.

\section{CONSTRUÇÃO DA IDENTIDADE}

Esta pesquisa mostra que assim como outros grupos que procuram alternativas ao modelo econômico capitalista, a COPAVI, assentamento-modelo do MST, percebe a necessidade de realizar um trabalho específico de conscientização e formação crítica e militante de suas crianças e jovens como complemento da educação formal/escolar. O MST valoriza e incentiva o ingresso de seus jovens na escola, mas acredita que essa formação não atende às necessidades de formação integral de seus membros, já que a educação escolar segue a ideologia da classe dominante.

Daí a importância da escola diferente proposta e realizada pela COPAVI, em que se valoriza uma educação pelo e para o trabalho, contextualizada com a vida do campo, com os valores humanistas, a cidadania, a criticidade e a gestão democrática entre educandos, educadores e comunidade. Trata-se, portanto, de educar a partir da prática para a construção comunitária e a participação ativa no coletivo, como aspectos imprescindíveis na luta pela cidadania.

A pesquisa revela também que na COPAVI a educação se dá por meio da comunicação horizontal entre educando e educador, característica que a diferencia e a torna mais significativa. Adepto aos ensinamentos de Paulo Freire, o assentamento procura desenvolver seu acompanhamento pedagógico com base numa educação que "é comunicação e diálogo, na medida em que não é transferência de saber, mas um encontro de sujeitos interlocutores que buscam a significação dos significados" ${ }^{14}$, comprovando que a "comunicação é um ato pedagógico e a educação é um ato comunicativo"15.

Segundo o Boletim de Educação,

As crianças e os jovens dos assentamentos já vivem ou até nascem como herdeiros das conquistas de dignidade. Mas não conseguirão manter e reproduzir estas
13. Ibid., p. 146.

14. LIMA, Venício A. Comunicação e cultura: as idéias de Paulo Freire. Rio de Janeiro: Paz e Terra, 1984. p. 59.

15. PERUZZO, Cecília M. K. Comunicação comunitária e educação para a cidadania. In: Revista Fronteiras: estudos midiáticos. São Leopoldo: Unisinos, v. 3, n. 1, set. 2001. 
conquistas, nem tampouco honrarão o nome próprio Sem-Terra, se não herdarem também a identidade coletiva construída no processo de luta. Só que valores e princípios não se herdam sem cultivo consciente, sem intencionalidade pedagógica de quem produz ou de quem os escolhe herdar ${ }^{16}$.

Daí a grande responsabilidade pelo cultivo dessa identidade que eles atribuem ao trabalho de educação junto às crianças e jovens do Movimento. Somase a isso o dever de formar cidadãos com postura não-conformista diante do mundo e com valores humanos que sustentem uma luta permanente pela vida.

Resumo: O texto apresenta como uma cooperativa de assentamento do Movimento dos Trabalhadores Rurais Sem-Terra trabalha a educação e a comunicação em sua comunidade. Na concepção do Movimento, educação não é somente sinônimo de ensino formal; ao contrário, tem um sentido muito mais amplo, pois diz respeito à complexidade do processo de formação humana, que tem nas práticas sociais o principal ambiente das aprendizagens do ser humano. A Cooperativa de Produção Agropecuária Vitória Ltda. - COPAVI, situada em Paranacity, no norte do estado do Paraná, investe desde 1991 na formação da identidade das 25 crianças (de 5 a 12 anos) que moram no assentamento.

Palavras-chave: comunicação, educação, movimento social e cidadania.
Absctract: The text shows how communication and education are worked in a settlement of the Brazilian Landless Workers Movement. In the Movement's understanding, education is not only synonym of formal teaching; on the contrary, it has a broader sense, because it is related to the complexity of the human formation process, where the social practices constitute the main environment of human learnings. The Cooperativa de Produção Agropecuária Vitória Ltda. - COPAVI, located in Paranacity, in Northern Parana State, is dedicated to the identity formation of 25 children (aged 5 to 12 years) that live in the settlement.

Keywords: communication; education; social movement and citizenship.
16. PEDAGOGIA..., op. cit., p. 28. 